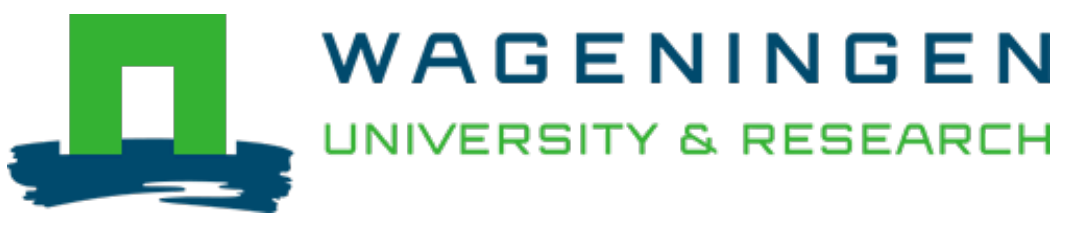

\title{
Microplastics are a hotspot for antibiotic resistance genes : Progress and perspective
}

\author{
Science of the Total Environment \\ Liu, Yi; Liu, Wenzhi; Yang, Xiaomei; Wang, Jie; Lin, Hui et al \\ https://doi.org/10.1016/j.scitotenv.2021.145643
}

This article is made publicly available in the institutional repository of Wageningen University and Research, under the terms of article $25 \mathrm{fa}$ of the Dutch Copyright Act, also known as the Amendment Taverne. This has been done with explicit consent by the author.

Article 25 fa states that the author of a short scientific work funded either wholly or partially by Dutch public funds is entitled to make that work publicly available for no consideration following a reasonable period of time after the work was first published, provided that clear reference is made to the source of the first publication of the work.

This publication is distributed under The Association of Universities in the Netherlands (VSNU) 'Article $25 \mathrm{fa}$ implementation' project. In this project research outputs of researchers employed by Dutch Universities that comply with the legal requirements of Article $25 \mathrm{fa}$ of the Dutch Copyright Act are distributed online and free of cost or other barriers in institutional repositories. Research outputs are distributed six months after their first online publication in the original published version and with proper attribution to the source of the original publication.

You are permitted to download and use the publication for personal purposes. All rights remain with the author(s) and / or copyright owner(s) of this work. Any use of the publication or parts of it other than authorised under article $25 \mathrm{fa}$ of the Dutch Copyright act is prohibited. Wageningen University \& Research and the author(s) of this publication shall not be held responsible or liable for any damages resulting from your (re)use of this publication.

For questions regarding the public availability of this article please contact openscience.library@wur.nl 
Review

\title{
Microplastics are a hotspot for antibiotic resistance genes: Progress and perspective
}

\author{
Yi Liu ${ }^{\mathrm{a}, \mathrm{b}, 1}$, Wenzhi Liu ${ }^{\mathrm{a}, \mathrm{b}, 1}$, Xiaomei Yang ${ }^{\mathrm{d}, \mathrm{e}}$, Jie Wang ${ }^{\mathrm{f}}$, Hui Lin ${ }^{\mathrm{g}}$, Yuyi Yang a,b,c,* \\ a Key Laboratory of Aquatic Botany and Watershed Ecology, Wuhan Botanical Garden, Chinese Academy of Sciences, Wuhan 430074, China \\ b Center of Plant Ecology, Core Botanical Gardens, Chinese Academy of Sciences, Wuhan 430074, China \\ c Sino-Africa Joint Research Center, Chinese Academy of Sciences, Wuhan 430074, China \\ d Soil Physics and Land Management Group, Wageningen University \& Research, Droevendaalsesteeg 4, 6708PB Wageningen, the Netherlands \\ e College of Natural Resources and Environment, Northwest AEF University, 712100 Yangling, China \\ ${ }^{\mathrm{f}}$ Beijing Key Laboratory of Farmland Soil Pollution Prevention and Remediation, College of Resources and Environmental Sciences, China Agricultural University, Beijing, 100193, China \\ ' The Institute of Environment, Resources, Soil and Fertilizers, Zhejiang Academy of Agricultural Sciences, Hangzhou 310021, China
}

\section{H I G H L I G H T S}

- ARGs on microplastics in WWTPs, water, soil, and air were summarized.

- Distinct ARG composition on microplastics was due to selective enrichment.

- Aggregates are crucial to study the transport and transfer of ARGs on microplastic.

\section{A R T I C L E I N F O}

\section{Article history:}

Received 29 October 2020

Received in revised form 30 January 2021

Accepted 31 January 2021

Available online 6 February 2021

Editor: Fang Wang

\section{Keywords:}

Microplastics

Transport

Aggregates

Resistome

Food web

\section{GRAPHICA L A B S T RACT}

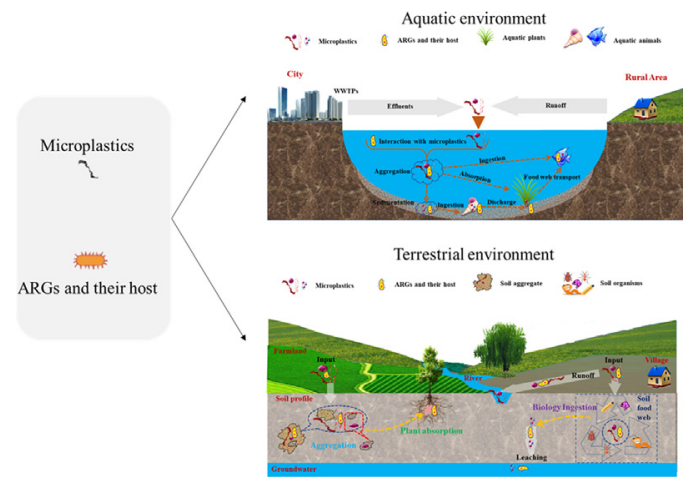

\begin{abstract}
A B S T R A C T
Antibiotic resistance genes (ARGs) and microplastics in the environment are of great public concern due to their potential risk to human health. Microplastics can form distinct bacterial communities and absorb pollutants from the surrounding environment, which provide potential hosts and exert possible selection pressure of ARGs. We provide a practical evaluation of the scientific literature regarding this issue. The occurrence and transport of ARGs on microplastics in wastewater treatment plants, aquatic, terrestrial, and air environments were summarized. Selective enrichment of ARGs and antibiotic resistance bacteria on microplastics have been confirmed in different environments. Aggregates may be crucial to understand the behavior and transport of ARGs on microplastics, especially in the aquatic and terrestrial environment. Microplastics could be a carrier of ARGs between the environment and animals. Accumulation of pollutants and dense bacterial communities on microplastics provide favorable conditions for higher transfer rate and evolution of ARGs. More studies are still needed to understand the enrichment, transport, and transfer of ARGs on microplastics and provide a fundamental basis for evaluating their exposure health risk to humans.
\end{abstract}

(c) 2021 Elsevier B.V. All rights reserved.

\footnotetext{
* Corresponding author at: Wuhan Botanical Garden, Chinese Academy of Sciences, Lumo Road No.1, Wuchang District, Wuhan, China.

E-mail address: yangyy@wbgcas.cn (Y. Yang).

1 The authors contributed equally to this manuscript.
} 


\section{Contents}

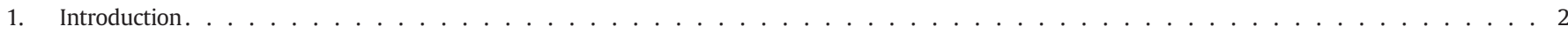

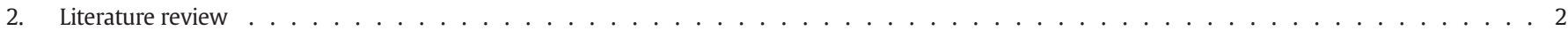

3. Occurrence of antibiotic resistance genes on microplastics . . . . . . . . . . . . . . . . . . . . . . . . . . . . . . . . . . . . . . . . . . . 2

3.1. Wastewater treatment plants (WWTPs) and landfill leachate . . . . . . . . . . . . . . . . . . . . 2

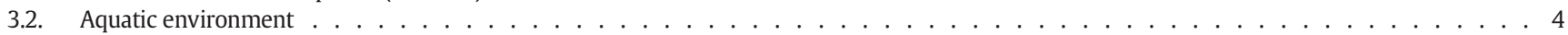

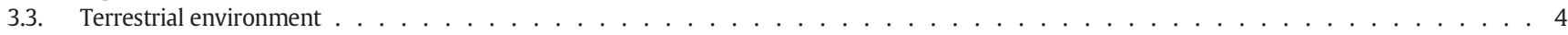

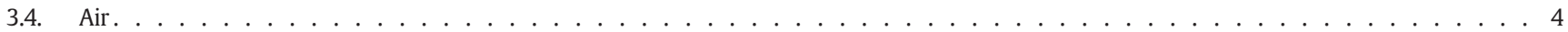

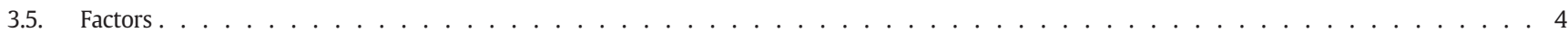

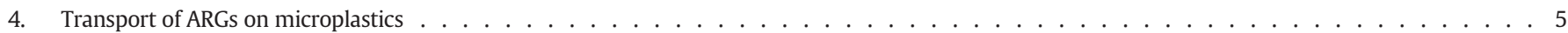

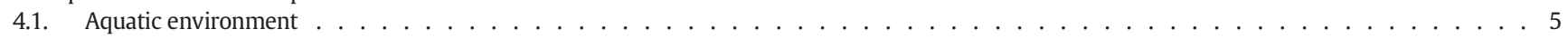

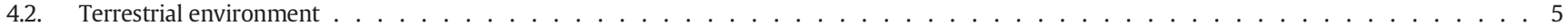

5. Transfer of antibiotic resistance genes on microplastics . . . . . . . . . . . . . . . . . . . . . . . . . . . . . 6

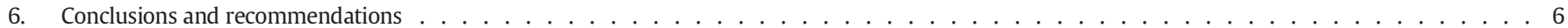

Declaration of competing interest. . . . . . . . . . . . . . . . . . . . . . . . . . . . . . . . . . . . . . .

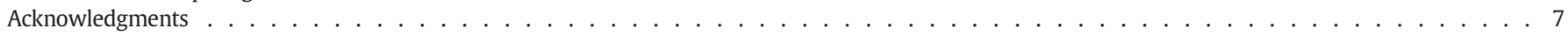

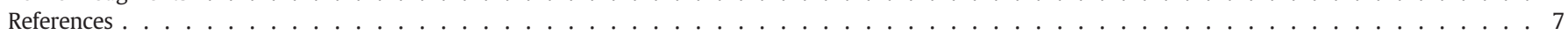

\section{Introduction}

Antibiotic resistance genes (ARGs) and microplastics in the environment are of great public concern due to their potential risk to human health. ARGs and microplastics are considered emerging pollutants in recent decades (Pruden et al., 2006; Thompson et al., 2004). ARGs have been ranked as a priority in the recent One Health operational framework (White and Hughes, 2019). Until now, more than 200 ARG subtypes are observed in different environments using metagenome or high-throughput PCR, such as global lake water (Yang et al., 2019a), Chinese croplands (Du et al., 2020), Chinese estuaries (Zhu et al., 2017), and River Ganges (Reddy and Dubey, 2019). The accumulation and spread of ARGs in bacteria have caused severe issues to the successful prevention and treatment of persistent diseases (Dadgostar, 2019). It has been estimated that about 10 million people could die, and $\$ 300$ billion to more than $\$ 1$ trillion costs could be paid annually by 2050 worldwide if no effective measure is taken against antimicrobial resistance (Chokshi et al., 2019; Dadgostar, 2019; Laxminarayan et al., 2013). The environment is considered to be important as well as human and aminals in the One Health operational framework (Finley et al., 2013). Humans could be exposed to ARGs and their host in the environment via various pathways, like drinking water (Collignon and McEwen, 2019). Therefore, the transport and transfer of ARGs will improve the understanding of potential risks of ARG exposure to humans.

Recently, microplastics not only provide a new microbial niche (Amaral-Zettler et al., 2020; Yang et al., 2020b; Zettler et al., 2013), but also serve as vectors for the transport of ARGs and harmful organisms (Keswani et al., 2016; Yang et al., 2019b). Selective enrichment of pathogens and antibiotic-resistant bacteria on microplastics have been proved (Wu et al., 2019; Zhang et al., 2020b). The existence of microplastic in air, soil, water, sediment, edible salt, and food provides various exposure pathways of ARGs, pollutants, and harmful organisms to plants, animals, and humans (Prata et al., 2020; Smith et al., 2018). Microplastics could transport or exchange the ARGs and other pollutants from different environmental compartments even at long distances (Koelmans et al., 2016; Schwarz et al., 2019). The occurrence, detection, and distribution of ARGs and microplastics have been reviewed in different environments, such as rivers (Koelmans et al., 2019; Singh et al., 2019), lakes (Li et al., 2018b; Yang et al., 2018), soil (Xie et al., 2018; Zhu et al., 2019), which is not the scope of this paper. In this manuscript, the distribution, transport, and transfer of ARGs on microplastics in different environments were summarized to (1) discover the current research status about ARGs on microplastics in wastewater treatment plants, water, soil, and air; (2) identify the potential transport of ARGs on microplastics in environments via food-web;
(3) uncover the possible transfer and evolution of ARGs on microplastics; (4) highlight the potential future research directions.

\section{Literature review}

To survey the antibiotic resistance genes on microplastics, we used the Web of Knowledge database (http://apps.webofknowledge.com) and databases of ScienceDirect (https://www.sciencedirect.com) to retrieve publications. [plastic AND antibiotic resistance genes], [microplastic AND antibiotic resistance genes], [plastic AND resistome], and [microplastic AND resistome] were used as the research terms. The database was searched for studies published up to 15 December 2020. Firstly, publications were checked individually to eliminate any duplicates or irrelevant articles. Ultimately, fifteen research papers reporting the antibiotic resistance genes on microplastic or plastic were found. Three papers were related to wastewater treatment plants (WWTPs) and landfill leachate, ten papers related to the aquatic environment, and two papers related to soil samples (Table 1). Conventional qPCR, HT-qPCR, and metagenomic methods were applied respectively in eight, two, and three papers to study ARG on microplastics.

\section{Occurrence of antibiotic resistance genes on microplastics}

\subsection{Wastewater treatment plants (WWTPS) and landfill leachate}

Wastewater treatment plants (WWTPs) are the hotspot of ARGs and microplastics (Carr et al., 2016; Guo et al., 2017; Rizzo et al., 2013; Sun et al., 2019), which are one of the main point-sources for the natural environment. Certain bacteria associated with antibiotic resistance colonized abundantly on microplastics in WWTPs, indicating microplastics are vectors and hotspots for ARGs and their transfer (Oberbeckmann et al., 2018). A microcosm study showed that polyvinyl chloride (PVC) microplastics were an essential vector for the pathogenic bacteria and resistance genes in sewage (Zhao et al., 2021). Recent studies showed that the enrichment of ARGs on microplastics in the field and microcosm experiments from WWTP and leachate depends on the polymer types, ARG subtypes, surrounding environment, and incubation time (Martínez-Campos et al., 2020; Su et al., 2021; Zhao et al., 2021). Long time (>60 days) incubation of microplastics in leachate or sewage would lead to a significant increase in ARG abundance on microplastics (Su et al., 2021; Zhao et al., 2021). The presence of pollutants, such as antibiotics or heavy metals in WWTP, could increase the ARG abundance on microplastics (Zhao et al., 2021). PVC, Polyethylene (PE), Polypropylene (PP), and polystyrene (PS) showed different preferences for the ARG. In the leachate microcosm, a higher abundance of ARGs was observed on PE microplastics than PP (Su et al., 2021). WWTPs consists 
Table 1

The relevant papers reporting antibiotic resistance genes on microplastics (MP).

\begin{tabular}{|c|c|c|c|c|}
\hline Source & $\begin{array}{l}\text { Sampling } \\
\text { design }\end{array}$ & $\begin{array}{l}\text { Method for } \\
\text { ARGs }\end{array}$ & Main results about ARGs & Reference \\
\hline \multicolumn{5}{|c|}{ WWTP and landfill leachate } \\
\hline Sewage & Microcosm & $\begin{array}{l}\text { qPCR for } 10 \\
\text { ARGs }\end{array}$ & $\begin{array}{l}\text { - The enrichment effect of ARGs on PVC MPs deepened on the incubation time. } \\
\text { - No enrichment effects of ARGs on PVC MPs were observed on the 28th day but observed on the 84th } \\
\text { day compared to the sewage system. } \\
\text { - The addition of antibiotics and heavy metals led to an increase in resistance genes abundances on } \\
\text { PVC MPs. }\end{array}$ & (Zhao et al., 2021) \\
\hline Landfill leachate & Microcosm & $\begin{array}{l}\text { qPCR for } 7 \\
\text { ARGs }\end{array}$ & $\begin{array}{l}\text { - Incubation time and microplastic type also influenced the enrichment effect of ARGs o } \\
\text { microplastics. } \\
\text { - PE showed a higher preference for ARG enrichment compared to PP. } \\
\text { - Microplastics had a } 5.7-10^{3} \text { times higher abundance of ARGs than leachate at } 60 \text { and } 90 \text { days } \\
\text { incubation. }\end{array}$ & (Su et al., 2021) \\
\hline WWTP effluents & Field & $\begin{array}{l}\text { qPCR for sulI } \\
\text { and tetM }\end{array}$ & $\begin{array}{l}\text { - The enrichment effect of ARGs on microplastics depended on polymer types, ARG subtypes, and the } \\
\text { surrounding environment. } \\
\text { - No significant differences were found in the relative abundances of sul1 and tetM between MP and } \\
\text { water in WWTP1. } \\
\text { - PS MPs had a higher abundance of sul1 than that water. }\end{array}$ & $\begin{array}{l}\text { (Martínez-Campos } \\
\text { et al., 2020) }\end{array}$ \\
\hline \multicolumn{5}{|c|}{ Aquatic environment } \\
\hline $\begin{array}{l}\text { Aquaculture } \\
\text { system }\end{array}$ & Field & $\begin{array}{l}\text { Cultivatable } \\
\text { method }\end{array}$ & $\begin{array}{l}\text { Microplastics had higher counts of cultivable antibiotic resistance genes, which were } 100-5000 \\
\text { times higher than those in water. } \\
\text { - Microplastic had more (five) of class } 1 \text { integrons (intI1) associated gene cassette arrays than those } \\
\text { in water. } \\
\text { - Higher positive detection rates of ARGs in bacteria isolates from microplastics were observed } \\
\text { compared with water samples. }\end{array}$ & $\begin{array}{l}\text { (Zhang et al., } \\
\text { 2020b) }\end{array}$ \\
\hline $\begin{array}{l}\text { Aquaculture } \\
\text { system }\end{array}$ & Field & $\begin{array}{l}\text { qPCR for } 10 \\
\text { ARGs }\end{array}$ & $\begin{array}{l}\text { - Microplastics with higher absolute abundance }\left(1.59-1.83 \times 10^{9} \text { copies } / \mathrm{g}\right) \text { compared with water } \\
\text { samples }\left(3.24-7.83 \times 10^{5} \text { copies } / \mathrm{mL}\right) \text {. } \\
\text { - Higher absolute abundances of } \text { int } 11 \text { were found on microplastics }\left(2.34 \times 10^{8}-4.99 \times 10^{8} \text { copies } / \mathrm{g}\right) \\
\text { compared with water }\left(1.02-5.70 \times 10^{5} \text { copies } / \mathrm{mL}\right) \\
\text { - The absolute abundances of ARGs on microplastics followed the order of } \text { sul }>\text { tet }>\text { qnr }>\text { erm. }\end{array}$ & (Lu et al., 2019) \\
\hline Estuary & Field & $\begin{array}{l}\text { qPCR for } 7 \\
\text { ARGs }\end{array}$ & $\begin{array}{l}\text { - Six ARGs showed enrichment effect on microplastics compared with water and sediment environ- } \\
\text { ment except for sul2, which had a higher abundance in the sediment. } \\
\text { - The absolute abundances of intI1 on microplastics }\left(1.03 \times 10^{8} \text { copies/g) were significantly higher }\right. \\
\text { than those in sediment ( } 3.40 \times 10^{5} \text { copies/g) and water }\left(2.75 \times 10^{3} \mathrm{copies} / \mathrm{mL}\right) \text {. } \\
\text { - polyethylene (PE) had a higher relative abundance of ARGs than polypropylene (PP) }\end{array}$ & (Guo et al., 2020) \\
\hline Swedish marina & Field & Metagenomics & $\begin{array}{l}\text { Only macrolide-lincosamide-streptogramin (MLS) and trimethoprim resistance genes were enriched } \\
\text { in the antifouling paint-selected plastic panel than those in unpainted one. While antibiotic resistance } \\
\text { genes conferring resistance to seven class antibiotics are higher in unpainted plastic panels. }\end{array}$ & (Flach et al., 2017) \\
\hline $\begin{array}{l}\text { The North Pacific } \\
\text { Gyre }\end{array}$ & Field & Metagenomics & $\begin{array}{l}\text { - Microplastic with a higher average relative abundance of total ARGs ( } 5.15 \times 10^{-3} \text { copies per } 16 \mathrm{~S} \\
\text { rRNA) compared with seawater }\left(9.06 \times 10^{-4} \text { copies per } 16 \mathrm{~S} \text { rRNA). }\right. \\
\text { - } 64 \text { and } 6 \text { ARG subtypes were found on microplastics and seawater samples, respectively. } \\
\text { Bacteria community was the main driver shaping the ARG profile, among which the family } \\
\text { Flavobacteriaceae may be important hosts for both ARGs. } \\
\text { - A higher incidence of non-random co-occurrence was found for some ARGs and metal resistance } \\
\text { genes, suggesting co-effects of selection existed. }\end{array}$ & $\begin{array}{l}\text { (Yang et al., } \\
\text { 2019b) }\end{array}$ \\
\hline Urban water & Field & HT-qPCR & $\begin{array}{l}\text { - } 82 \text { ARGs and } 12 \text { MGEs were observed on microplastics, which were lower than those in water (120 } \\
\text { ARGs and } 28 \text { MGEs) } \\
\text { - The diversity of both ARGs and MEGs in microplastic biofilm was generally lower than that in water } \\
\text { - Plastisphere had a distinct antibiotic resistome compared with water. }\end{array}$ & $\begin{array}{l}\text { (Yang et al., } \\
2020 a \text { ) }\end{array}$ \\
\hline Freshwater & Bioreactor & Metagenomics & $\begin{array}{l}\text { - The ARG abundance (188 subtypes) on polyvinyl chloride microplastics was nearly three times } \\
\text { higher than those in river water ( } 67 \text { subtypes). } \\
\text { - Specific ARG types (e.g, Daunorubicin and fosfomycin) in the water had higher relative abundance } \\
\text { than those on microplastics. } \\
\text { - Unique ARG profiles on microplastic were: smeE, mdsC, qnrVC6, ermF, lnuE, blaVEB-9, aadA13, APH } \\
\text { (9)-Ia, APH(300)-VI, aadA16, fosK, arr-5, cmx, dfrA15. }\end{array}$ & (Wu et al., 2019) \\
\hline $\begin{array}{l}\text { River, estuary and } \\
\text { marine water }\end{array}$ & Microcosm & $\begin{array}{l}\text { qPCR for } 8 \\
\text { ARGs }\end{array}$ & $\begin{array}{l}\text { - Most ARGs were found to be enriched on polyethylene microplastics. } \\
\text { - polyethylene microplastics showed selective enrichment for sul1, tetC, tetX, and ermE but not for } \\
\text { sulA/folP-01and tetA }\end{array}$ & $\begin{array}{l}\text { (Wang et al., } \\
\text { 2020b) }\end{array}$ \\
\hline Urban river & Field & $\begin{array}{l}\text { qPCR for } 25 \\
\text { ARGs }\end{array}$ & $\begin{array}{l}\text { - The relative abundance of ARGs on microplastics }\left(0.79-5.7 \times 10^{-2} \text { copies per } 16 \mathrm{~S} \text { rRNA) were }\right. \\
\text { significantly lower than those in water }\left(2.3-6.4 \times 10^{-2} \text { copies per } 16 \mathrm{~S} \text { rRNA). }\right. \\
\text { - Specific ARG subtypes (tetM, tetS, and tetW) had higher relative abundance on microplastics com- } \\
\text { pared with water. } \\
\text { - Principal component analysis indicated microplastics had distinct ARG profiles from water. }\end{array}$ & $\begin{array}{l}\text { (Wang et al., } \\
\text { 2020a) }\end{array}$ \\
\hline River water & Bioreactor & qPCR for sul1 & - No obvious enrichment effect of ARGs on microplastics was found. & $\begin{array}{l}\text { (Parrish and } \\
\text { Fahrenfeld, 2019) }\end{array}$ \\
\hline \multicolumn{5}{|c|}{ Terrestrial environment } \\
\hline Soil ${ }^{\mathrm{T}}$ & $\begin{array}{l}\text { Column } \\
\text { experiment }\end{array}$ & $\begin{array}{l}\text { PCR for } \\
\text { qualitative } \\
\text { analysis }\end{array}$ & - Five (tetA, tetX, sul1, sul2, and bla ${ }_{\mathrm{TEM}}$ ) of 12 tested ARGs were observed on microplastics. & (Yan et al., 2020) \\
\hline $\begin{array}{l}\text { Facility vegetable } \\
\text { soil }\end{array}$ & Field & HT-qPCR & $\begin{array}{l}\text { - Larger MPs had higher ARG abundance than those of smaller MPs. } \\
\text { - Strongly aged MPs also had higher ARG abundance compared to weakly aged ones. } \\
\text { - There is a higher abundance in ARG on MPs after ten planting years than three planting years. }\end{array}$ & (Lu et al., 2020) \\
\hline
\end{tabular}


of several stages for wastewater treatment, including aerated process, primary sedimentation tank, anoxic tank, secondary sedimentation tank, and chlorination disinfection process. However, there is very little information about the transport of ARGs on microplastics during the different stages. Although WWTPs were found to remove microplastics efficiently, they are still primary sources for microplastics entering terrestrial and aquatic ecosystems (Raju et al., 2018; Zhang and Chen, 2020), especially for sludge (Rolsky et al., 2020; Sun et al., 2019). It should be noted that the residue microplastics also caused changes of ARG propagation in sewage in an aerobic granular sludge system (Dai et al., 2020), the leachate solution (Shi et al., 2020), and the river water receiving treated wastewater (Eckert et al., 2018).

\subsection{Aquatic environment}

Ten papers related to ARGs on microplastics in the aquatic environment were summarized, among which six studies showed that microplastics enriched ARGs (Guo et al., 2020; Lu et al., 2019; Raju et al., 2018; Wang et al., 2020a; Wang et al., 2020b; Wu et al., 2019; Yang et al., 2019b) (Table 1). It was also found that most studies focused on ARGs on the microplastics in the waterbody, not the sediment, which might be attributed to the difficulties in the recovery and identification of microplastic biofilm in benthic conditions (Van Cauwenberghe et al., 2015). Microplastics from North Pacific Gyre (Yang et al., 2019b) and freshwater bioreactor (Wu et al., 2019) showed higher abundance and diversity of ARGs compared to surrounding water via metagenomic analysis. In the human-impacted aquacultural system, both culturedependent and culture-independent methods proved that the abundance of antibiotic resistance bacteria and ARGs were several orders of magnitude than those in water samples (Lu et al., 2019; Zhang et al., 2020b). While, a field incubation experiment found that microplastics usurally had lower diversity and richness of ARGs compared with water using HT-PCR (Yang et al., 2020a). Microplastics collected from the urban river with unknowing incubation time also showed lower relative abundances of 25 ARGs than those in water samples via qPCR (Wang et al., 2020a). Polymer types also exhibited different performances on the ARG enrichment on microplastics from the aquatic environment. For example, PE collected from the estuary was observed with a higher ARG abundance than PP (Guo et al., 2020), which was similar to those observed in leachate microcosm (Su et al., 2021). Without regarding the abundance, ARG composition on microplastics was distinct from the surrounding environment (Wang et al., 2020a; Wu et al., 2019; Yang et al., 2020a).

The difference in ARG composition on various microplastics may be attributed to the selective enrichment of specific bacteria and ARGs from the surrounding environment. The distinct bacteria communities colonized on microplastics in the aquatic environment have been regarded as a new microbial niche (Amaral-Zettler et al., 2020; Yang et al., 2020b; Zettler et al., 2013). Some specific potential hosts of ARGs were enriched or even only found on microplastics, such as Pseudomonas monteilii, Pseudomonas mendocina, and Pseudomonas syringae (Wu et al., 2019). In a microcosm experiment, sul1, tetC, tetX, and ermE were selectively enriched on PE microplastics, but sulA/ folP-01and tetA were not (Wang et al., 2020b). Additives or pollutants accumulated on microplastics are also important factors influencing the selective enrichment of ARGs. The antifouling paint plastic panel containing copper and zinc showed preference for macrolidelincosamide-streptogramin (MLS) and trimethoprim resistance genes compared to unpainted ones (Flach et al., 2017).

\subsection{Terrestrial environment}

Microplastics have been widely found in farmland soil, which can change not only the biophysical characteristics (de Souza Machado et al., 2018; He et al., 2018) but also the microbial communities and resistome in the soil environment (Chen et al., 2020b; Huang et al.,
2019; Sun et al., 2018). Furthermore, specific microorganisms colonized on the microplastics formed distinct microbial communities from soils (Zhang et al., 2019a). ARGs on microplastics are dependent on the specific colonized bacteria from the soil (Zhang et al., 2019a), but also shaped by pollutants like pesticides, heavy metals from the soil, or additives exerting selective pressure on the microplastics (Koelmans et al., 2016; Wang et al., 2019a). However, only two studies directly focused on the distribution and transport of ARGs on microplastics from soils (Lu et al., 2020; Yan et al., 2020). The fewer studies have limited our full understanding of ARGs on microplastics in the terrestrial environment. Qualitative analysis showed that ARGs on the microplastics could be vertically transported in soil (Yan et al., 2020). Lu et al. (2020) found that larger, strongly weathered microplastics and long years of cultivation generally led to an increase in the abundance of ARGs on microplastics in the facility vegetable soil. Selective enrichment of ARGs is dependent on the size, weathering status of microplastics, characteristics of soil (e.g., years of cultivation), and specific ARG types. For example, sulfonamide-ARGs and macrolide-lincosamidestreptogramin B (MLSB) resistance genes were selectively enriched on heavily weathered microplastics, while beta-lactamase and aminoglycoside resistance genes showed a preference for slightly weathered microplastics (Lu et al., 2020).

\subsection{Air}

ARGs and microplastics in the air could not only be transported to remote areas via wind (Evangeliou et al., 2020; Li et al., 2018a) but also directly exert harmful effects on human or animal health via inhalation (Xie et al., 2019; Zhang et al., 2020a). The distribution of ARGs and microplastics in the air have been studied, respectively (Chen et al., 2020a; Li et al., 2018a; Xie et al., 2019). The $\beta$-lactam resistance gene bla $_{T E M}$, and quinolone resistance gene qepA were abundant ARGs in the air from a global survey (Li et al., 2018a). In highly polluted air, the clinical resistance gene $b l a_{\mathrm{NDM}-1}$ conferring resistance to carbapenems, which was used as a last resort in tertiary care hospitals, was detected up to $30 \%$ of total ARG abundance in heavily polluted air (Zhang et al., 2019b). Different bacteria taxa, including human opportunistic pathogens (e.g., Comamonas Testosteroni and Moraxella Osloensis), accounted for the airborne ARGs (Li et al., 2018a; Li et al., 2016). It was also estimated that 21 microplastic particles are potentially inhaled by an adult in Shanghai every day (Liu et al., 2019). Microplastics with concentrations of 1.7-16.2 particles $\mathrm{m}^{-3}$ were also found in the indoor environment (Vianello et al., 2019). Furthermore, synthetic fibers have already been detected in human lung biopsies (Prata, 2018). However, no study about ARGs on microplastics in the outdoor and indoor air was reported until now. The studies about ARGs on microplastics in the air will be critical to estimate their combination risk for human health via inhalation and long-distance transport capacity via wind.

\subsection{Factors}

Fig. 1 summarizes the factors involved in the study about ARGs on microplastics based on Table 1: detection methods, sampling design, microplastic characteristics, and environmental conditions. There are no standardized methods for the design and uniform detection methods of ARGs on microplastics, which leads to difficulties in comparing different studies. For example, even for the metagenomic method, the different pipeline processes and databases used in the analysis also lead to a less rigorous comparison. Besides, the numbers of detected ARGs on microplastics for conventional qPCR were in a wide range of 1-25 (Table 1). Incubation time is one of the key factors explaining the formation and composition of ARGs on microplastics, which should be provided in the sampling design or collection. A detailed description of microplastics (e.g., polymer type, size, shape) and environmental conditions on this topic is essential to understand the enrichment process and comparison of ARGs on microplastics between different studies. 


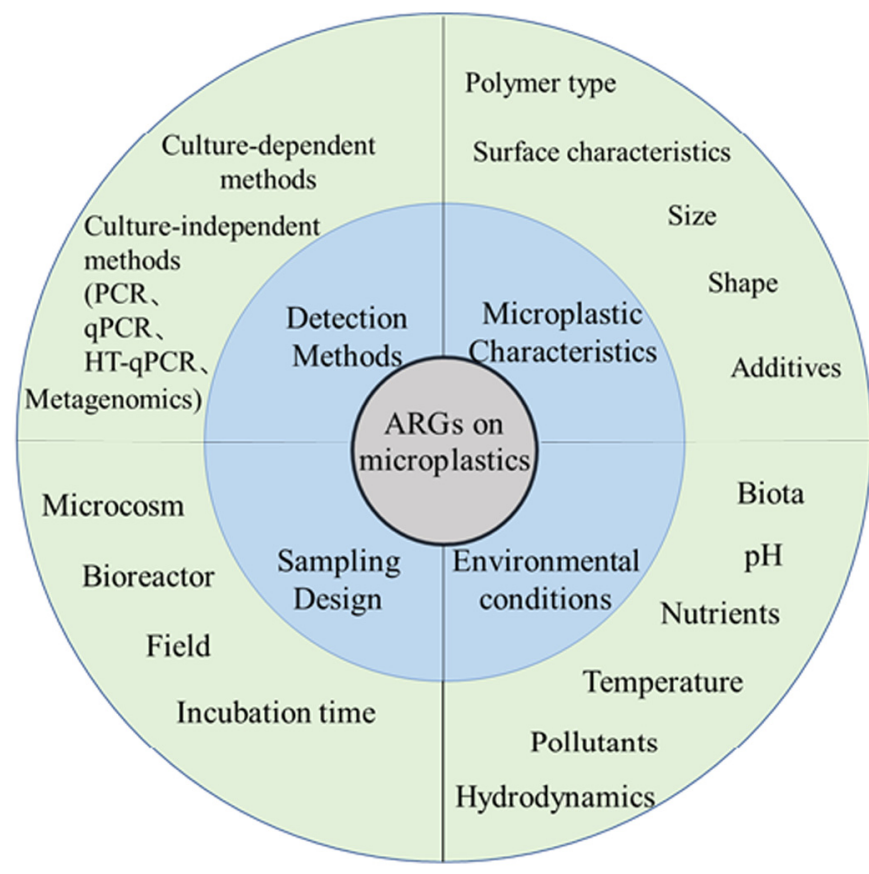

Fig. 1. Factors involved in the study o ARGs on microplastics.

\section{Transport of ARGs on microplastics}

\subsection{Aquatic environment}

The aquatic environment is one of the main reservoirs for microplastics discharged from WWTPs, industries, and agricultural activities (Fig. 2). Microplastics can interact with the widely existed natural colloids and microorganisms to form aggregates in the aquatic environment (Alimi et al., 2018; Leiser et al., 2021; Wang et al., 2021). The aggregates can significantly influence the environmental behavior of microplastic, such as adsorption, sedimentation, and trophic transport (Long et al., 2015; Zhao et al., 2018), which affect the fate of ARGs on microplastics. Aggregates facilitate sedimentation and enhance the transport of microplastics and their associated contaminants (e.g., heavy metals) to food webs (Alimi et al., 2018; Zhao et al., 2018). As shown in Fig. 2, microplastic aggregates can be adsorbed and captured by aquatic plants (Kalčíková, 2020; Yu et al., 2020) and ingested by aquatic animals (Jabeen et al., 2017; Neves et al., 2015). The adsorbed PE microplastics induced microbiota dysbiosis and inflammation in the gut of adult zebrafish (Jin et al., 2018), and microplastics developed a similar bacterial community as the gut microbiome after passing through the gut of Mytilus edulis (Kesy et al., 2017). The potential host of ARGs on microplastics, such as fish pathogen Flavobacteriaceae (Yang et al., 2019b), can enhance the exchange and evolution of ARGs after interaction between microplastics and the gut microbiome. In the future, the shared ARGs between environment, microplastics, and aquatic biota may be needed more attention due to their potential mobility and evolution between different media.

\subsection{Terrestrial environment}

Sewage sludge, organic fertilizers, plastic film mulching, atmospheric deposition, and irrigation were summarized as the primary sources of microplastics in the terrestrial environment (Wang et al., 2020c). The interaction between soil and microplastics could form different aggregates. Soil aggregates play a key role in the horizontal and downward transport of pollutants (like ARGs, microplastics, heavy metals) in the agroecosystems via runoff (Astner et al., 2020; Rillig et al., 2017a; Xu et al., 2017) (Fig. 3). Microplastics aggregated with soil minerals were identified as the critical driver mechanism for the downward transport of aged microplastics and their associated ARGs in natural loamy sand (Yan et al., 2020). Microplastic fibers dominated soil micro-aggregate, while films and fragments were more distributed on macro-aggregate (Zhang and Liu, 2018). The inhibition effects of organic matter in micro-aggregates were significantly higher than those in macro-aggregates on the vertical transport of nanoparticles (Xu et al., 2019). The micro-aggregates were more susceptible to soil erosion than macroaggregates, which finally affected the vertical and horizontal transport of particles via runoff (Lu et al., 2016) (Fig. 3). Different distribution patterns of microbial communities are found between the soil macro-aggregates and micro-aggregates (Wang et al., 2019b; Wilpiszeski et al., 2019), which may host different ARGs. Therefore, soil aggregates would be essential to understand the transport and transfer of ARGs on microplastics and their interactions with soil resistome (Fig. 3).

Recently, ARGs and microplastics were transported or transferred from soil to edible vegetables, respectively (Li et al., 2020; Zhang et al., 2019c). The interactions in resistome between microplastics and vegetables are still unclear. Compared to plants, it is easy to understand

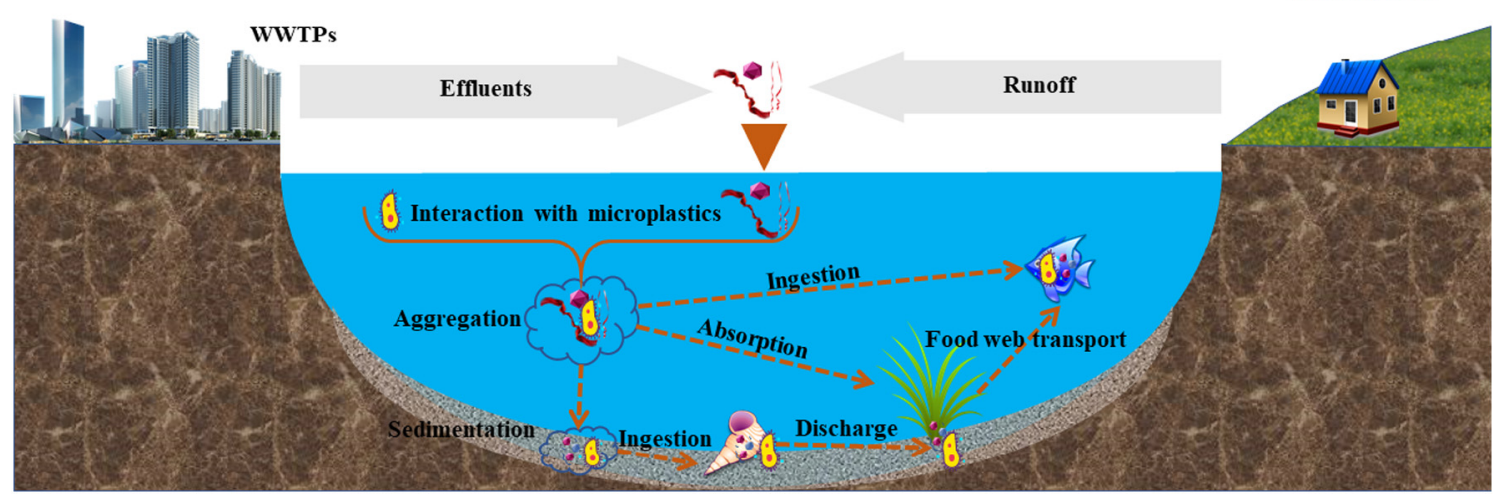

Fig. 2. The transport of ARGs on microplastics in the aquatic environment. 


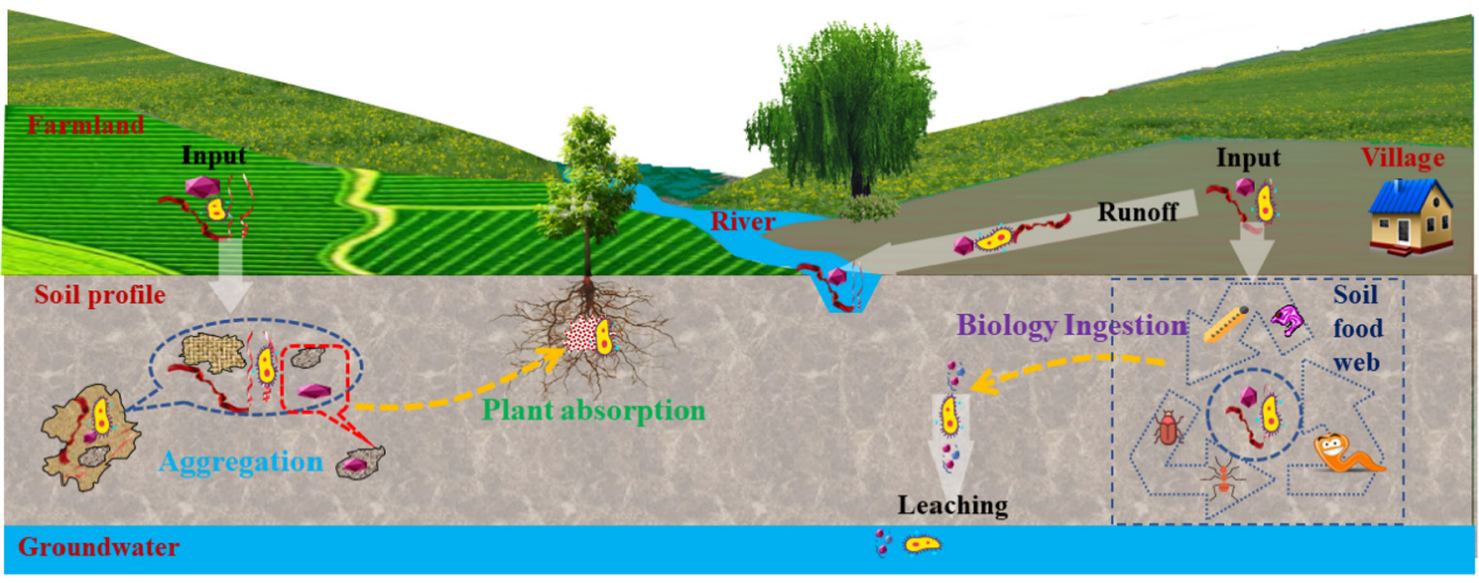

Fig. 3. The transport of ARGs on microplastics in the terrestrial environment.

the transport of ARGs on microplastics from soil to animals. Microplastics and their adsorbed pollutants, such as pesticides, could be accumulated in soil earthworms (Rillig et al., 2017b; RodríguezSeijo et al., 2019). It has been proved that microplastics alone can disturb the gut microbiome of soil animals, such as collembolans (Folsomia candida) (Ju et al., 2019; Zhu et al., 2018). Microplastics, combined with tetracycline, have been observed to facilitate antibiotic resistance in the gut microbiome of the Enchytraeus crypticus (Ma et al., 2020). Although microplastics were a vector of ARGs in soils (Lu et al., 2020), less is know about the effect and transport of ARGs on microplastics in the terrestrial environment.

\section{Transfer of antibiotic resistance genes on microplastics}

Microplastic is a hotspot for vector and transfer of ARGs between different bacterial taxa in the environment (Imran et al., 2019). Pollutants absorbed and dense biofilm structure formed on microplastics highlighted the spread risk of ARGs via transfer. Microplastics with high specific surface area and hydrophobicity in the water, soil, and air are favorable for the accumulation of pollutants (e.g., heavy metals, antibiotics) (Guo et al., 2019; Koelmans et al., 2016) and colonization of ARG host (e.g., Flavobacteriaceae) (Keswani et al., 2016; Lagana et al., 2019; Yang et al., 2019b). It also has been observed that the number of antibiotic-resistant bacteria on microplastics was 100-5000 times higher than those in the surrounding water (Zhang et al., 2020b). Similarly, bacterial pathogens as potential ARG hosts were enriched on microplastics, such as Flavobacterium and Chryseobacterium (Gong et al., 2019; Wu et al., 2019). Antibiotics on microplastics could directly influence the horizontal and vertical gene transfer of ARGs in bacterial communities. For example, the presence of trimethoprim significantly increased both the horizontal and vertical gene transfer rates of ARGs on plasmids (Li et al., 2019). The inorganic pollutants (e.g., heavy metals) and other organic pollutants (e.g., polycyclic aromatic hydrocarbons) could exert selection pressure on the ARG transfer via coselection or cross-selection (Imran et al., 2019). The high density of bacteria, including antibiotic-resistant bacteria on microplastics, could form a denser biofilm structure (Dussud et al., 2018; Zhang et al., 2020b). The colony-forming units ( $\mathrm{CFU}$ ) of total cultivable bacteria on microplastics were $1.44-2.80 \times 10^{8} \mathrm{CFU} / \mathrm{g}$, which were significantly higher than those in water samples $\left(0.29-3.0 \times 10^{6} \mathrm{CFU} / \mathrm{mL}\right.$ ) (Zhang et al., 2020b). Bacteria isolated from plastics can produce extracellular polymer substances, which is also favorable for the formation of denser bacterial communities (Lagana et al., 2019; Lagarde et al., 2016). Denser bacterial community on microplastics enhanced the horizontal gene transfer rate of ARGs on mobile genetic elements (MGEs) between different taxa. Microcosm experiment showed that uptake frequency of plasmid in bacterial communities on microplastics was two orders of magnitude higher than those observed in free-living bacteria (Arias-Andres et al., 2018). The higher horizontal gene transfer rate of ARGs on microplastics may lead to a higher abundance of MGEs with a more diverse ARG composition (Table 1) (Lu et al., 2019; Zhang et al., 2020b). Higher numbers and types of class 1 integrons (intI1) associated with ARG cassette arrays were found in the multi-antibiotic resistant bacteria from microplastics compared with water (Lu et al., 2019; Zhang et al., 2020b). These studies provided direct evidence of the diversity of MGEs with ARGs on microplastics, which could promote the transfer and evolution of ARGs in bacterial communities on microplastics. Therefore, pollutants, aggregates, and denser bacteria communities are favorable for higher transfer rates and the evolution of ARGs on microplastics.

\section{Conclusions and recommendations}

ARGs on microplastics are an emerging issue with great public concern due to their potential risk for the ecosystem and human health. Distinct ARG composition has been proved on microplastics, although no consensus was obtained comparing the abundance and diversity between microplastics and the surrounding environment. Selective enrichment of ARGs and antibiotic-resistant bacteria is one of the primary mechanisms for the distinct ARG profile on microplastics. The summarized factors in the ARGs on microplastics suggested that much more key information should be provided to compare different studies, such as detection methods, microplastic type, environmental conditions, and sampling design. Field collection and microcosm experiments shed light on the enrichment of ARGs on microplastics (Table 1), but in situ experiments will be helpful to understand the selective enrichment process of ARGs in the real environment. More studies are still needed to discover the environmental behavior and ecotoxicity of ARGs on microplastics in the future.

Enrichment of ARGs on microplastics depended on the microplastic characteristics, surrounding environment (including pollutants), and incubation time (Fig. 1). However, the specific enrichment process of ARGs in different stages of WWTPs (e.g., anoxic stages, primary settling tank, selector tank, aerated tank), different aquatic environment with nutrients and hydraulic characteristics (e.g., eutrophic lake, tidal and 
coastal environment), different soil types (e.g., sand, and clay) and air environment are still needed to get a comprehensive understanding about the role of environmental factors on the enrichment of ARGs on microplastics. Non-degradable microplastics are the main studied targets for ARG enrichment (Table 1) and biofilm formation (Yang et al., 2020b). While the degradable plastic particles discharged into the environment will increase because even biodegradable plastics are not $100 \%$ degradable (Shen et al., 2020; Shruti and Kutralam-Muniasamy, 2019). Hence, the microplastic characteristics, such as polymer types (e.g., Non-degradable and degradable plastics), the aging process (e.g., UV), and morphology (e.g., size and shape), are still needed to understand their roles in ARG enrichment.

Microplastics formed distinct bacterial communities compared to the surrounding environment. Core resistome has been discovered in urban sewage and soil (Du et al., 2020; Su et al., 2017). Continuous efforts are needed to study the core resistome on microplastics and shared resistome with the surrounding environment, which is crucial to understand the potential risk of ARGs on microplastics. The intracellular and extracellular ARGs are both present in the environment, but less is known about their distribution in microplastic biofilm. The extracellular polymer substances are also the main components of biofilm and may result in the selection for antibiotic resistance (Amarasiri et al., 2020). The biofilm formed on microplastics is heterogeneous, with direct spatial relationships between bacteria, cyanobacteria, and eukaryotes (Schlundt et al., 2020). Therefore, it is indispensable to conduct more field studies to examine the composition, spatial distribution, transfer, and evolution of ARGs on microplastic biofilm. Aggregates in water, air, and soil play an essential role in the transport of ARGs on microplastics. What are the factors influencing the downward and runoff transport of ARGs on microplastics associated aggregates? Additionally, the role of microplastics associated aggregates in the transfer of ARGs through food webs (from the environment to plants, animals, and humans) also remains to be clarified.

\section{Declaration of competing interest}

All authors have read and approve this version of the article, and due care has been taken to ensure the integrity of the work. No part of this paper has been published or submitted elsewhere. No conflict of interest exits in the submission of this manuscript.

\section{Acknowledgments}

This work was supported by the National Natural Science Foundation of China [Grant NO. 32071614], the Starting Research Fund from Key Laboratory of Aquatic Botany and Watershed Ecology, Chinese Academy of Sciences [Grant NO. Y9519802] and Funding Project of Sino-Africa Joint Research Center, Chinese Academy of Sciences [Grant NO. E0291P0101].

\section{References}

Alimi, O.S., Farner Budarz, J., Hernandez, L.M., Tufenkji, N., 2018. Microplastics and nanoplastics in aquatic environments: aggregation, deposition, and enhanced contaminant transport. Environ. Sci. Technol. 52, 1704-1724.

Amaral-Zettler, L.A., Zettler, E.R., Mincer, T.J., 2020. Ecology of the plastisphere. Nat. Rev. Microbiol. 18, 139-151.

Amarasiri, M., Sano, D., Suzuki, S., 2020. Understanding human health risks caused by antibiotic resistant bacteria (ARB) and antibiotic resistance genes (ARG) in water environments: current knowledge and questions to be answered. Crit. Rev. Environ. Sci. Technol. 50, 2016-2059.

Arias-Andres, M., Klumper, U., Rojas-Jimenez, K., Grossart, H.P., 2018. Microplastic pollution increases gene exchange in aquatic ecosystems. Environ. Pollut. 237, 253-261.

Astner, A.F., Hayes, D.G., Pingali, S.V., O'Neill, H.M., Littrell, K.C., Evans, B.R., Urban, V.S., 2020. Effects of soil particles and convective transport on dispersion and aggregation of nanoplastics via small-angle neutron scattering (SANS) and ultra SANS (USANS). PLoS One 15, e0235893.

Carr, S.A., Liu, J., Tesoro, A.G., 2016. Transport and fate of microplastic particles in wastewater treatment plants. Water Res. 91, 174-182.
Chen, G., Feng, Q., Wang, J., 2020a. Mini-review of microplastics in the atmosphere and their risks to humans. Sci. Total Environ. 703, 135504.

Chen, H., Wang, Y., Sun, X., Peng, Y., Xiao, L., 2020b. Mixing effect of polylactic acid microplastic and straw residue on soil property and ecological function. Chemosphere 243, 125271.

Chokshi, A., Sifri, Z., Cennimo, D., Horng, H., 2019. Global contributors to antibiotic resistance. J. Glob. Infect. Dis. 11, 36-42.

Collignon, P.J., McEwen, S.A., 2019. One health-its importance in helping to better control antimicrobial resistance. Trop. Med. Infect. Dis. 4, 22. https://doi.org/10.3390/ tropicalmed4010022.

Dadgostar, P., 2019. Antimicrobial resistance: implications and costs. Infect. Drug Resist. $12,3903-3910$.

Dai, H.-H., Gao, J.-F., Wang, Z.-Q., Zhao, Y.-F., Zhang, D., 2020. Behavior of nitrogen, phosphorus and antibiotic resistance genes under polyvinyl chloride microplastics pressures in an aerobic granular sludge system. J. Clean. Prod. 256, 120402.

Du, S., Shen, J.-P., Hu, H.-W., Wang, J.-T., Han, L.-L., Sheng, R., Wei, W.-X., Fang, Y.-T., Zhu, Y.-G., Zhang, L.-M., He, J.-Z., 2020. Large-scale patterns of soil antibiotic resistome in Chinese croplands. Sci. Total Environ. 712, 136418.

Dussud, C., Meistertzheim, A.L., Conan, P., Pujo-Pay, M., George, M., Fabre, P., Coudane, J., Higgs, P., Elineau, A., Pedrotti, M.L., Gorsky, G., Ghiglione, J.F., 2018. Evidence of niche partitioning among bacteria living on plastics, organic particles and surrounding seawaters. Environ. Pollut. 236, 807-816.

Eckert, E.M., Di Cesare, A., Kettner, M.T., Arias-Andres, M., Fontaneto, D., Grossart, H.-P., Corno, G., 2018. Microplastics increase impact of treated wastewater on freshwater microbial community. Environ. Pollut. 234, 495-502.

Evangeliou, N., Grythe, H., Klimont, Z., Heyes, C., Eckhardt, S., Lopez-Aparicio, S., Stohl, A., 2020. Atmospheric transport is a major pathway of microplastics to remote regions. Nat. Commun. 11, 3381.

Finley, R.L., Collignon, P., Larsson, D.G., McEwen, S.A., Li, X.Z., Gaze, W.H., Reid-Smith, R., Timinouni, M., Graham, D.W., Topp, E., 2013. The scourge of antibiotic resistance: the important role of the environment. Clin. Infect. Dis. 57, 704-710.

Flach, C.F., Pal, C., Svensson, C.J., Kristiansson, E., Ostman, M., Bengtsson-Palme, J., Tysklind, M., Larsson, D.G.J., 2017. Does antifouling paint select for antibiotic resistance? Sci. Total Environ. 590, 461-468.

Gong, M., Yang, G., Zhuang, L., Zeng, E.Y., 2019. Microbial biofilm formation and community structure on low-density polyethylene microparticles in lake water microcosms. Environ. Pollut. 252, 94-102.

Guo, J., Li, J., Chen, H., Bond, P.L., Yuan, Z., 2017. Metagenomic analysis reveals wastewater treatment plants as hotspots of antibiotic resistance genes and mobile genetic elements. Water Res. 123, 468-478.

Guo, X., Liu, Y., Wang, J.L., 2019. Sorption of sulfamethazine onto different types of microplastics: a combined experimental and molecular dynamics simulation study. Mar. Pollut. Bull. 145, 547-554.

Guo, X.-P., Sun, X.-L., Chen, Y.-R., Hou, L., Liu, M., Yang, Y., 2020. Antibiotic resistance genes in biofilms on plastic wastes in an estuarine environment. Sci. Total Environ. 745, 140916.

He, D., Luo, Y., Lu, S., Liu, M., Song, Y., Lei, L., 2018. Microplastics in soils: analytical methods, pollution characteristics and ecological risks. TrAC Trend. Anal. Chem. 109, 163-172.

Huang, Y., Zhao, Y., Wang, J., Zhang, M., Jia, W., Qin, X., 2019. LDPE microplastic films alter microbial community composition and enzymatic activities in soil. Environ. Pollut. 254, 112983.

Imran, M., Das, K.R., Naik, M.M., 2019. Co-selection of multi-antibiotic resistance in bacterial pathogens in metal and microplastic contaminated environments: An emerging health threat. Chemosphere 215, 846-857.

Jabeen, K., Su, L., Li, J., Yang, D., Tong, C., Mu, J., Shi, H., 2017. Microplastics and mesoplastics in fish from coastal and fresh waters of China. Environ. Pollut. 221, 141-149.

Jin, Y., Xia, J., Pan, Z., Yang, J., Wang, W., Fu, Z., 2018. Polystyrene microplastics induce microbiota dysbiosis and inflammation in the gut of adult zebrafish. Environ. Pollut. 235, 322-329.

Ju, H., Zhu, D., Qiao, M., 2019. Effects of polyethylene microplastics on the gut microbial community, reproduction and avoidance behaviors of the soil springtail, Folsomia candida. Environ. Pollut. 247, 890-897.

Kalčíková, G., 2020. Aquatic vascular plants - a forgotten piece of nature in microplastic research. Environ. Pollut. 262, 114354.

Keswani, A., Oliver, D.M., Gutierrez, T., Quilliam, R.S., 2016. Microbial hitchhikers on marine plastic debris: human exposure risks at bathing waters and beach environments. Mar. Environ. Res. 118, 10-19.

Kesy, K., Hentzsch, A., Klaeger, F., Oberbeckmann, S., Mothes, S., Labrenz, M., 2017. Fate and stability of polyamide-associated bacterial assemblages after their passage through the digestive tract of the blue mussel Mytilus edulis. Mar. Pollut. Bull. 125, 132-138.

Koelmans, A.A., Bakir, A., Burton, G.A., Janssen, C.R., 2016. Microplastic as a vector for chemicals in the aquatic environment: critical review and model-supported reinterpretation of empirical studies. Environ. Sci. Technol. 50, 3315-3326.

Koelmans, A.A., Mohamed Nor, N.H., Hermsen, E., Kooi, M., Mintenig, S.M., De France, J., 2019. Microplastics in freshwaters and drinking water: critical review and assessment of data quality. Water Res. 155, 410-422.

Lagana, P., Caruso, G., Corsi, I., Bergami, E., Venuti, V., Majolino, D., La Ferla, R., Azzaro, M., Cappello, S., 2019. Do plastics serve as a possible vector for the spread of antibiotic resistance? First insights from bacteria associated to a polystyrene piece from King George Island (Antarctica). Int. J. Hyg. Environ. Health 222, 89-100.

Lagarde, F., Olivier, O., Zanella, M., Daniel, P., Hiard, S., Caruso, A., 2016. Microplastic interactions with freshwater microalgae: hetero-aggregation and changes in plastic density appear strongly dependent on polymer type. Environ. Pollut. 215, 331-339. 
Laxminarayan, R., Duse, A., Wattal, C., Zaidi, A.K., Wertheim, H.F., Sumpradit, N., Vlieghe, E., Hara, G.L., Gould, I.M., Goossens, H., Greko, C., So, A.D., Bigdeli, M., Tomson, G., Woodhouse, W., Ombaka, E., Peralta, A.Q., Qamar, F.N., Mir, F., Kariuki, S., Bhutta, Z.A., Coates, A., Bergstrom, R., Wright, G.D., Brown, E.D., Cars, O., 2013. Antibiotic resistance-the need for global solutions. Lancet Infect. Dis. 13, 1057-1098.

Leiser, R., Jongsma, R., Bakenhus, I., Möckel, R., Philipp, B., Neu, T.R., Wendt-Potthoff, K., 2021. Interaction of cyanobacteria with calcium facilitates the sedimentation of microplastics in a eutrophic reservoir. Water Res. 189, 116582.

Li, J., Zhou, L., Zhang, X., Xu, C., Dong, L., Yao, M., 2016. Bioaerosol emissions and detection of airborne antibiotic resistance genes from a wastewater treatment plant. Atmos. Environ. 124, 404-412.

Li, J., Cao, J., Zhu, Y.-g., Chen, Q.-l., Shen, F., Wu, Y., Xu, S., Fan, H., Da, G., Huang, R.-j., Wang, J., de Jesus, A.L., Morawska, L., Chan, C.K, Peccia, J., Yao, M., 2018a. Global survey of antibiotic resistance genes in air. Environ. Sci. Technol 52, 10975-10984.

Li, J., Liu, H., Paul Chen, J., 2018b. Microplastics in freshwater systems: a review on occurrence, environmental effects, and methods for microplastics detection. Water Res. 137, 362-374.

Li, B., Qiu, Y., Song, Y., Lin, H., Yin, H., 2019. Dissecting horizontal and vertical gene transfer of antibiotic resistance plasmid in bacterial community using microfluidics. Environ. Int. 131, 105007.

Li, L., Luo, Y., Li, R., Zhou, Q., Peijnenburg, W.J.G.M., Yin, N., Yang, J., Tu, C., Zhang, Y., 2020. Effective uptake of submicrometre plastics by crop plants via a crack-entry mode. Nat. Sustain. https://doi.org/10.1038/s41893-020-0567-9.

Liu, K., Wang, X., Fang, T., Xu, P., Zhu, L., Li, D., 2019. Source and potential risk assessment of suspended atmospheric microplastics in Shanghai. Sci. Total Environ. 675, 462-471.

Long, M, Moriceau, B, Lambert, C, Huvet, A, Raffray, J, Soudant, P, 2015. Interactions between microplastics and phytoplankton aggregates: impact on their respective fates. Mar. Chem. 175, 39-46.

Lu, J., Zheng, F., Li, G., Bian, F., An, J., 2016. The effects of raindrop impact and runoff detachment on hillslope soil erosion and soil aggregate loss in the Mollisol region of Northeast China. Soil Tillage Res. 161, 79-85.

Lu, J., Zhang, Y.X., Wu, J., Luo, Y.M., 2019. Effects of microplastics on distribution of antibiotic resistance genes in recirculating aquaculture system. Ecotoxicol. Environ. Saf. $184,109631$.

Lu, X.M., Lu, P.Z., Liu, X.P., 2020. Fate and abundance of antibiotic resistance genes on microplastics in facility vegetable soil. Sci. Total Environ. 709, 136276.

Ma, J., Sheng, G.D., O'Connor, P., 2020. Microplastics combined with tetracycline in soils facilitate the formation of antibiotic resistance in the Enchytraeus crypticus microbiome. Environ. Pollut. 264, 114689

Martínez-Campos, S., González-Pleiter, M., Fernández-Piñas, F., Rosal, R., Leganés, F., 2020. Early and differential bacterial colonization on microplastics deployed into the effluents of wastewater treatment plants. Sci. Total Environ 143832.

Neves, D., Sobral, P., Ferreira, J.L., Pereira, T., 2015. Ingestion of microplastics by commercial fish off the Portuguese coast. Mar. Pollut. Bull. 101, 119-126.

Oberbeckmann, S., Kreikemeyer, B., Labrenz, M., 2018. Environmental factors support the formation of specific bacterial assemblages on microplastics. Front. Microbiol. 8. https://doi.org/10.3389/fmicb.2017.02709.

Parrish, K., Fahrenfeld, N.L., 2019. Microplastic biofilm in fresh- and wastewater as a function of microparticle type and size class. Environ. Sci.-Water Res. Technol. 5, 495-505.

Prata, J.C., 2018. Airborne microplastics: consequences to human health? Environ. Pollut. 234, 115-126.

Prata, J.C., da Costa, J.P., Lopes, I., Duarte, A.C., Rocha-Santos, T., 2020. Environmental exposure to microplastics: An overview on possible human health effects. Sci. Total Environ. 702,134455 .

Pruden, A., Pei, R., Storteboom, H., Carlson, K.H., 2006. Antibiotic resistance genes as emerging contaminants: studies in northern Colorado. Environ. Sci. Technol. 40, 7445-7450.

Raju, S., Carbery, M., Kuttykattil, A., Senathirajah, K., Subashchandrabose, S.R., Evans, G., Thavamani, P., 2018. Transport and fate of microplastics in wastewater treatment plants: implications to environmental health. Rev. Environ. Science and BioTechnol. 17, 637-653.

Reddy, B., Dubey, S.K., 2019. River Ganges water as reservoir of microbes with antibiotic and metal ion resistance genes: high throughput metagenomic approach. Environ. Pollut. 246, 443-451.

Rillig, M.C., Ingraffia, R., de Souza Machado, A.A., 2017a. Microplastic incorporation into soil in agroecosystems. Front. Plant Sci. 8, 1805.

Rillig, M.C., Ziersch, L., Hempel, S., 2017b. Microplastic transport in soil by earthworms. Sci. Rep. 7, 1362.

Rizzo, L., Manaia, C., Merlin, C., Schwartz, T., Dagot, C., Ploy, M.C., Michael, I., FattaKassinos, D., 2013. Urban wastewater treatment plants as hotspots for antibiotic resistant bacteria and genes spread into the environment: a review. Sci. Total Environ. 447, 345-360.

Rodríguez-Seijo, A., Santos, B., Ferreira da Silva, E., Cachada, A., Pereira, R., 2019. Lowdensity polyethylene microplastics as a source and carriers of agrochemicals to soil and earthworms. Environ. Chem. 16, 8-17.

Rolsky, C., Kelkar, V., Driver, E., Halden, R.U., 2020. Municipal sewage sludge as a source of microplastics in the environment. Curr. Opin. Environ. Sci. Health 14, 16-22.

Schlundt . Mark, C., Welch, J.L., Knochel, A.M., Zettler, E.R., Amaral-Zettler, L.A., 2020. Spatial structure in the "Plastisphere": molecular resources for imaging microscopic communities on plastic marine debris. Mol. Ecol. Resour. 20, 620-634.

Schwarz, A.E., Ligthart, T.N., Boukris, E., van Harmelen, T., 2019. Sources, transport, and accumulation of different types of plastic litter in aquatic environments: a review study. Mar. Pollut. Bull. 143, 92-100.
Shen, M., Song, B., Zeng, G., Zhang, Y., Huang, W., Wen, X., Tang, W., 2020. Are biodegradable plastics a promising solution to solve the global plastic pollution? Environ. Pollut. 263, 114469 .

Shi, J., Wu, D., Su, Y., Xie, B., 2020. (Nano)microplastics promote the propagation of antibiotic resistance genes in landfill leachate. Environ. Sci. Nano 7, 3536-3546.

Shruti, V.C., Kutralam-Muniasamy, G., 2019. Bioplastics: missing link in the era of microplastics. Sci. Total Environ. 697, 134139.

Singh, R., Singh, A.P., Kumar, S., Giri, B.S., Kim, K.-H., 2019. Antibiotic resistance in major rivers in the world: a systematic review on occurrence, emergence, and management strategies. J. Clean. Prod. 234, 1484-1505.

Smith, M., Love, D.C., Rochman, C.M., Neff, R.A., 2018. Microplastics in seafood and the implications for human health. Curr. Environ. Health Rep. 5, 375-386.

de Souza Machado, A.A., Lau, C.W., Till, J., Kloas, W., Lehmann, A., Becker, R., Rillig, M.C., 2018. Impacts of microplastics on the soil biophysical environment. Environ. Sci. Technol. 52, 9656-9665.

Su, J.-Q., An, X.-L., Li, B., Chen, Q.-L., Gillings, M.R., Chen, H., Zhang, T., Zhu, Y.-G., 2017. Metagenomics of urban sewage identifies an extensively shared antibiotic resistome in China. Microbiome 5, 84

Su, Y., Zhang, Z., Zhu, J., Shi, J., Wei, H., Xie, B., Shi, H., 2021. Microplastics act as vectors for antibiotic resistance genes in landfill leachate: the enhanced roles of the long-term aging process. Environ. Pollut. 270, 116278.

Sun, M., Ye, M., Jiao, W., Feng, Y., Yu, P., Liu, M., Jiao, J., He, X., Liu, K., Zhao, Y., Wu, J., Jiang, $\mathrm{X}$., Hu, F., 2018. Changes in tetracycline partitioning and bacteria/phage-comediated ARGs in microplastic-contaminated greenhouse soil facilitated by sophorolipid. J. Hazard. Mater. 345, 131-139.

Sun, J., Dai, X., Wang, Q., van Loosdrecht, M.C.M., Ni, B.-J., 2019. Microplastics in wastewater treatment plants: detection, occurrence and removal. Water Res. 152, 21-37.

Thompson, R.C., Olsen, Y., Mitchell, R.P., Davis, A., Rowland, S.J., John, A.W.G., McGonigle, D., Russell, A.E., 2004. Lost at sea: where is all the plastic? Science 304, 838.

Van Cauwenberghe, L., Devriese, L., Galgani, F., Robbens, J., Janssen, C.R., 2015 Microplastics in sediments: a review of techniques, occurrence and effects. Mar. Environ. Res. 111, 5-17.

Vianello, A., Jensen, R.L., Liu, L., Vollertsen, J., 2019. Simulating human exposure to indoor airborne microplastics using a Breathing Thermal Manikin. Sci. Rep. 9, 8670

Wang, J., Liu, X., Li, Y., Powell, T., Wang, X., Wang, G., Zhang, P., 2019a. Microplastics as contaminants in the soil environment: a mini-review. Sci. Total Environ. 691, 848-857.

Wang, L., Luo, X., Xiong, X., Chen, W., Hao, X., Huang, Q., 2019b. Soil aggregate stratification of ureolytic microbiota affects urease activity in an inceptisol. J. Agric. Food Chem. 67, 11584-11590.

Wang, J., Qin, X., Guo, J., Jia, W., Wang, Q., Zhang, M., Huang, Y., 2020a. Evidence of selective enrichment of bacterial assemblages and antibiotic resistant genes by microplastics in urban rivers. Water Res. 183, 116113.

Wang, S.S., Xue, N.N., Li, W.F., Zhang, D.Y., Pan, X.L., Luo, Y.M., 2020b. Selectively enrichment of antibiotics and ARGs by microplastics in river, estuary and marine waters. Sci. Total Environ. 708, 134594.

Wang, W., Ge, J., Yu, X., Li, H., 2020c. Environmental fate and impacts of microplastics in soil ecosystems: progress and perspective. Sci. Total Environ. 708, 134841.

Wang, X., Bolan, N., Tsang, D.C.W., Sarkar, B., Bradney, L., Li, Y., 2021. A review of microplastics aggregation in aquatic environment: influence factors, analytical methods, and environmental implications. J. Hazard. Mater. 402, 123496.

White, A., Hughes, J.M., 2019. Critical importance of a one health approach to antimicrobial resistance. EcoHealth 16, 404-409.

Wilpiszeski, R.L., Aufrecht, J.A., Retterer, S.T., Sullivan, M.B., Graham, D.E., Pierce, E.M., Zablocki, O.D., Palumbo, A.V., Elias, D.A., 2019. Soil aggregate microbial communities: towards understanding microbiome interactions at biologically relevant scales. Appl. Environ. Microbiol. 85 (e00324-19).

Wu, X., Pan, J., Li, M., Li, Y., Bartlam, M., Wang, Y., 2019. Selective enrichment of bacterial pathogens by microplastic biofilm. Water Res. 165, 114979.

Xie, W.Y., Shen, Q., Zhao, F.J., 2018. Antibiotics and antibiotic resistance from animal manures to soil: a review. Eur. J. Soil Sci. 69, 181-195.

Xie, J., Jin, L., He, T., Chen, B., Luo, X., Feng, B., Huang, W., Li, J., Fu, P., Li, X., 2019. Bacteria and antibiotic resistance genes (ARGs) in PM2.5 from China: implications for human exposure. Environ. Sci. Technol. 53, 963-972.

Xu, L., Cui, H., Zheng, X., Zhou, J., Zhang, W., Liang, J., Zhou, J., 2017. Changes in the heavy metal distributions in whole soil and aggregates affected by the application of alkaline materials and phytoremediation. RSC Adv. 7, 41033-41042.

Xu, S., Chen, X., Zhuang, J., 2019. Opposite influences of mineral-associated and dissolved organic matter on the transport of hydroxyapatite nanoparticles through soil and aggregates. Environ. Res. 171, 153-160.

Yan, X.Y., Yang, X.Y., Tang, Z., Fu, J.J., Chen, F.M., Zhao, Y., Ruan, L.L., Yang, Y.S., 2020. Downward transport of naturally-aged light microplastics in natural loamy sand and the implication to the dissemination of antibiotic resistance genes. Environ. Pollut. 262, 8.

Yang, Y., Song, W., Lin, H., Wang, W., Du, L., Xing, W., 2018. Antibiotics and antibiotic resistance genes in global lakes: a review and meta-analysis. Environ. Int. 116, 60-73.

Yang, Y., Li, Z., Song, W., Du, L., Ye, C., Zhao, B., Liu, W., Deng, D., Pan, Y., Lin, H., Cao, X., 2019a. Metagenomic insights into the abundance and composition of resistance genes in aquatic environments: influence of stratification and geography. Environ. Int. 127, 371-380.

Yang, Y.Y., Liu, G.H., Song, W.J., Ye, C., Lin, H., Li, Z., Liu, W.Z., 2019b. Plastics in the marine environment are reservoirs for antibiotic and metal resistance genes. Environ. Int. 123, 79-86.

Yang, K., Chen, Q.-L., Chen, M.-L., Li, H.-Z., Liao, H., Pu, Q., Zhu, Y.-G., Cui, L., 2020a. Temporal dynamics of antibiotic resistome in the plastisphere during microbial colonization. Environ. Sci. Technol. 54, 11322-11332. 
Yang, Y., Liu, W., Zhang, Z., Grossart, H.-P., Gadd, G.M., 2020b. Microplastics provide new microbial niches in aquatic environments. Appl. Microbiol. Biotechnol. 104, 6501-6511.

Yu, H., Zhang, X., Hu, J., Peng, J., Qu, J., 2020. Ecotoxicity of polystyrene microplastics to submerged carnivorous Utricularia vulgaris plants in freshwater ecosystems. Environ. Pollut. 265, 114830.

Zettler, E.R., Mincer, T.J., Amaral-Zettler, L.A., 2013. Life in the "Plastisphere”: microbial communities on plastic marine debris. Environ. Sci. Technol. 47, 7137-7146.

Zhang, Z., Chen, Y., 2020. Effects of microplastics on wastewater and sewage sludge treatment and their removal: a review. Chem. Eng. J. 382, 122955.

Zhang, G.S., Liu, Y.F., 2018. The distribution of microplastics in soil aggregate fractions in southwestern China. Sci. Total Environ. 642, 12-20.

Zhang, M., Zhao, Y., Qin, X., Jia, W., Chai, L., Huang, M., Huang, Y., 2019a. Microplastics from mulching film is a distinct habitat for bacteria in farmland soil. Sci. Total Environ. $688,470-478$.

Zhang, T., Li, X., Wang, M., Chen, H., Yang, Y., Chen, Q.-1, Yao, M., 2019b. Time-resolved spread of antibiotic resistance genes in highly polluted air. Environ. Int. 127, 333-339.

Zhang, Y.-J., Hu, H.-W., Chen, Q.-L., Singh, B.K., Yan, H., Chen, D., He, J.-Z., 2019c. Transfer of antibiotic resistance from manure-amended soils to vegetable microbiomes. Environ. Int. 130, 104912.
Zhang, Q., Xu, E.G., Li, J., Chen, Q., Ma, L., Zeng, E.Y., Shi, H., 2020a. A review of microplastics in table salt, drinking water, and air: direct human exposure. Environ. Sci. Technol. 54, 3740-3751

Zhang, Y.X., Lu, J., Wu, J., Wang, J.H., Luo, Y.M., 2020b. Potential risks of microplastics combined with superbugs: enrichment of antibiotic resistant bacteria on the surface of microplastics in mariculture system. Ecotoxicol. Environ. Saf. 187, 109852.

Zhao, S., Ward, J.E., Danley, M., Mincer, T.J., 2018. Field-based evidence for microplastic in marine aggregates and mussels: implications for trophic transfer. Environ. Sci. Technol. 52, 11038-11048.

Zhao, Y., Gao, J., Wang, Z., Dai, H., Wang, Y., 2021. Responses of bacterial communities and resistance genes on microplastics to antibiotics and heavy metals in sewage environment. J. Hazard. Mater. 123550

Zhu, Y.-G., Zhao, Y., Li, B., Huang, C.-L., Zhang, S.-Y., Yu, S., Chen, Y.-S., Zhang, T., Gillings, M.R., Su, J.-Q., 2017. Continental-scale pollution of estuaries with antibiotic resistance genes. Nat. Microbiol. 2, 16270.

Zhu, D., Chen, Q.-L., An, X.-L., Yang, X.-R., Christie, P., Ke, X., Wu, L.-H., Zhu, Y.-G., 2018. Exposure of soil collembolans to microplastics perturbs their gut microbiota and alters their isotopic composition. Soil Biol. Biochem. 116, 302-310.

Zhu, F., Zhu, C., Wang, C., Gu, C., 2019. Occurrence and ecological impacts of microplastics in soil systems: a review. Bull. Environ. Contam. Toxicol. 102, 741-749. 